\title{
Propofol-Induced Mitochondrial and Contractile Dysfunction of the Rat Ventricular Myocardium
}

\author{
M. GRUNDMANOVÁ ${ }^{1,2^{*}}$, D. JARKOVSKÁ ${ }^{1,2^{*}}$, A. SÜB ${ }^{1}$, Z. TƯMA ${ }^{2}$, M. MARKOVÁ ${ }^{1}$, \\ Z. GRUNDMAN ${ }^{1}$, A. EL-KADI ${ }^{1}$, M. ČEDÍKOVÁ ${ }^{1,2}$, M. ŚTENGL ${ }^{1,2}$, J. KUNCOVÁ ${ }^{1,2,3}$ \\ ${ }^{*}$ These authors contributed equally to the study.
}

${ }^{1}$ Department of Physiology, Faculty of Medicine in Pilsen, Charles University, Pilsen, Czech Republic, ${ }^{2}$ Biomedical Center, Faculty of Medicine in Pilsen, Charles University, Pilsen, Czech Republic, ${ }^{3}$ Department of Biophysics, Faculty of Medicine in Pilsen, Charles University, Pilsen, Czech Republic

Received March 27, 2016

Accepted October 26, 2016

\section{Summary}

Propofol is a short-acting hypnotic agent used in human medicine for sedation and general anesthesia. Its administration can be associated with serious cardiovascular side-effects that include decrease in arterial blood pressure and cardiac output. The aim of the present study was to evaluate propofol effects on mitochondrial respiration, myocardial contractility and electrophysiology in the same samples isolated from the heart ventricles of adult rats. Mitochondrial oxygen consumption was measured in permeabilized samples dissected from free walls of both ventricles using high-resolution respirometry. State LEAK was determined with malate and glutamate. Active respiration was induced by ADP (state PI) and further by succinate, a Complex II substrate (PI+II). Rotenone was injected to measure state PII. Antimycin A, a Complex III inhibitor was used to determine residual oxygen consumption (ROX). N,N,N',N'tetramethyl-p-phenylenediamine dihydrochloride and ascorbate were injected simultaneously for respirometric assay of cytochrome c oxidase activity (CIV). Isometric contractions and membrane potentials were determined on multicellular preparations isolated from right and left ventricles. Propofol concentrations used ranged from 0.005 to $0.5 \mathrm{mmol} / \mathrm{l}$. All respiratory parameters were significantly higher in the left control ventricles compared to the right ones. Propofol significantly decreased Complex I activity at concentration $0.025 \mathrm{mmol} / \mathrm{l}$ and papillary muscle contraction force at $0.1 \mathrm{mmol} / \mathrm{l}$. Propofol did not affect action potential duration at any concentration studied. Our study suggests that mechanisms contributing to the impaired myocardial contraction during propofol anesthesia might include also mitochondrial dysfunction manifested by compromised activity of the respiratory Complex I.

\section{Key words}

Propofol • High-resolution respirometry $\bullet$ Contractility $\bullet$ Rat heart - Action potential duration

\section{Corresponding author}

J. Kuncová, Department of Physiology, Biomedical Center, Faculty of Medicine in Pilsen, Charles University, Alej Svobody 76, 32300 Plzeň, Czech Republic. E-mail: jitka.kuncova@lfp.cuni.cz

\section{Introduction}

Propofol (2,6-diisopropylphenol) is a shortacting hypnotic agent used in human medicine for sedation and general anesthesia (Bryson et al. 1995). Its administration can be associated with serious cardiovascular side-effects that include decrease in arterial blood pressure and cardiac output (Yang et al. 2015). In rare cases, propofol causes life-threatening propofol infusion syndrome characterized by bradycardia, severe arrhythmias, rhabdomyolysis of the myocardium and skeletal muscles, heart failure, renal insufficiency, hepatomegaly and metabolic acidosis (Krajčová et al. 2015).

Many direct effects of propofol on cardiomyocytes potentially causing dose-dependent decrease in cardiac contractility have been suggested to 
date. They include calcium-related events on both sarcolemmal and subcellular levels: decrease in ICaL amplitude (Liu et al. 2008), modulation of Na-Ca exchange activity (Wickley et al. 2007), decrease in sarcoplasmic reticulum calcium load (Sprung et al. 2001) or impaired sensitivity of myofilaments to calcium ions (Wickley et al. 2006). In contrast, data documenting no significant impact of propofol on cardiac contractility have been also repeatedly reported (Riou et al. 1992, van Klarenbosch et al. 2001). Concerning the influence of propofol on mitochondria, both harmful and beneficial effects have been recorded to date. Recently, Vanlander et al. (2015) have suggested possible mechanism of propofol infusion syndrome via impeding the electron flow through respiratory chain and coenzyme Q. On the other hand, potential protective effects of propofol on ischemia-induced myocardial injury mediated by mitochondrial ATP-sensitive potassium channels, inhibition of the mitochondrial permeability transition (Sztark et al. 1995) or limitation of reactive oxygen species production in mitochondria have been documented (Shao et al. 2008). As these contradictory results could arise from various experimental setups, where animals of different species, strains and ages were used in addition to wide range of propofol concentrations in a variety of vehicle solutions, we have decided to test effects of propofol on membrane electrophysiology, force of contraction and mitochondrial oxygen consumption in multicellular preparations isolated from both ventricles of male adult rats.

\section{Methods}

\section{Animals and experimental design}

A total of 37 Wistar 6-month-old male rats (VELAZ, Prague, Czech Republic) were used for all experiments conducted in accordance with the European Directive for the Protection of Vertebrate Animals Used for Experimental and Other Scientific Purposes (86/609/EU) and the relevant Guidelines of the Czech Ministry of Agriculture for Scientific Experimentation on Animals and approved by the University Committee for Experiments on Laboratory Animals. We used exclusively mature adult male rats to reduce the number of animals required to perform all planned experiments and to gain results comparable to available experimental data. At the day of experiment, animals were killed by cervical dislocation and their hearts were quickly excised. For electrophysiological measurements, the papillary muscles were dissected from both left and right ventricles. For high-resolution respirometry, small samples (approx. $20 \mathrm{mg}$ of tissue) were taken from the subendocardial layer of anterior free walls of both ventricles. If not stated otherwise, all chemicals were of analytical grade and were purchased from Sigma-Aldrich (Prague, Czech Republic).

\section{High resolution respirometry}

Samples of ventricular tissues were placed into ice-cold preservation BIOPS solution of the following composition (in mmol/1): $\mathrm{CaK}_{2}$ EGTA 2.77, $\mathrm{K}_{2}$ EGTA 7.23, $\mathrm{Na}_{2}$ ATP 5.77, $\mathrm{MgCl}_{2} \cdot 6 \mathrm{H}_{2} \mathrm{O}$ 6.56, taurine 20, $\mathrm{Na}_{2}$ Phosphocreatine 15, imidazole 20, dithiothreitol 0.5 and MES hydrate 50 at pH 7.1 and $0{ }^{\circ} \mathrm{C}$ (Kuznetsov et al. 2004) and gently mechanically permeabilized with a pair of sharp forceps to get a specimen approximately doubled in volume and pale in color (Pesta and Gnaiger 2012).

Then the fibers were added into BIOPS containing saponin $(50 \mu \mathrm{g} / \mathrm{ml})$ for $10 \mathrm{~min}$ and washed twice with respiration medium with catalase (MiR06) for $10 \mathrm{~min}$. MiR06 contains (in mmol/l): EGTA 0.5, $\mathrm{MgCl}_{2} \cdot 6 \mathrm{H}_{2} \mathrm{O} \quad 3$, K-lactobionate 60 , taurine 20, $\mathrm{KH}_{2} \mathrm{PO}_{4} 10$, Hepes 20, sucrose 110 , and fatty acid free bovine serum albumin $1 \mathrm{~g} / \mathrm{l}$ at $\mathrm{pH} 7.1$ and $37^{\circ} \mathrm{C}$ (Pesta and Gnaiger 2012). The fibers were then blotted dry, weighed, and used for high-resolution respirometry.

Oxygen consumption by cardiac muscle fibers was measured at $37^{\circ} \mathrm{C}$ in 2-ml glass chambers of oxygraph Oroboros (Oroboros, Innsbruck, Austria) connected to the computer with DatLab software for data acquisition and analysis (Oroboros, Innsbruck, Austria). All oxygen fluxes were corrected for instrumental and chemical background measured in separate experiments performed in the same medium without biological samples.

After equilibration (40 min with air), oxygen concentration in the chamber corresponded to its concentration in the atmospheric air and solubility in the medium (0.92). Then, permeabilized fibers were added into the medium, the chambers were closed and oxygen concentration was raised to $400-500 \mathrm{mmol} / \mathrm{l}$ by titration of $\mathrm{H}_{2} \mathrm{O}_{2}(200 \mathrm{mmol} / \mathrm{l})$. After stabilization, combination of substrates and inhibitors was sequentially injected into the chambers to measure the respiration through different segments of the electron transport system (SUIT protocol; Fig. 1): 1) Resting respiration with substrates providing electrons to Complex I malate $(2 \mathrm{mmol} / \mathrm{l})$ and glutamate $(10 \mathrm{mmol} / \mathrm{l})$ was measured as a state $\mathrm{S} 2$ (non- 
phosphorylating LEAK state, L). 2) Active respiration was induced by $5 \mathrm{mmol} / \mathrm{l}$ adenosine diphosphate (ADP; state S3 or OXPHOS; PI). 3) Integrity of the mitochondrial inner membrane was checked with cytochrome c $(10 \mu \mathrm{mol} / \mathrm{l})$. 4) Mitochondrial respiration was then increased by succinate, a Complex II substrate (10 mmol/1; PI+II). 5) After addition of a Complex I inhibitor rotenone, the oxygen flux corresponded to maximum capacity of the electron-transporting system with the Complex II only (PII). 6) Then, antimycin A ( $2.5 \mu \mathrm{mol} / \mathrm{l})$, a Complex III inhibitor was injected into the chambers to measure residual oxygen consumption (ROX). 7) N,N,N',N'-tetramethyl-p-phenylenediamine dihydrochloride (TMPD; $0.5 \mathrm{mmol} / \mathrm{l}$ ) and ascorbate ( $2 \mathrm{mmol} / \mathrm{l}$ ) were injected simultaneously for respirometric assay of cytochrome c oxidase activity (CIV).

Propofol was dissolved in absolute ethanol and injected into the chambers $20 \mathrm{~min}$ prior to the SUIT protocol in concentrations ranging from $0.005 \mathrm{mmol} / 1$ to $0.5 \mathrm{mmol} / \mathrm{l}$. The volume of ethanol injected was $1 \mu \mathrm{l}$ per chamber. The effect of ethanol (up to $5 \mu \mathrm{l}$ ) on oxygen flux was measured in separate experiments; no changes in respirometric parameters were detected.

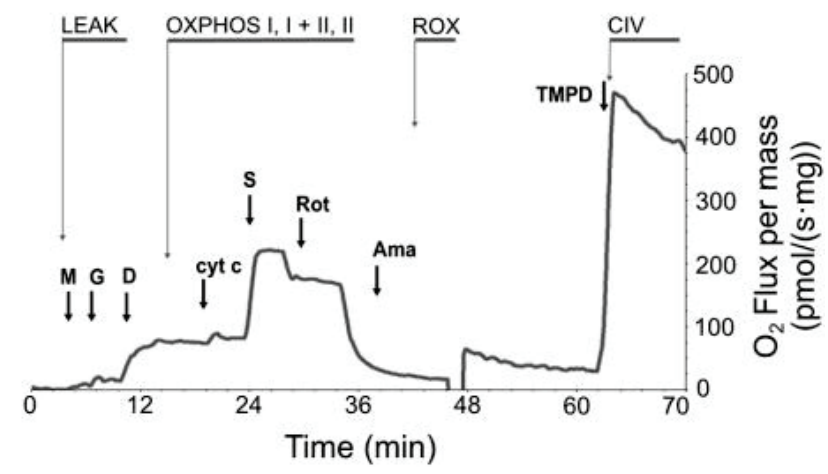

Fig. 1. Substrate-uncoupler-inhibitor titration (SUIT) protocol with substrates for Complex I, Complex II, and Complex IV in the rat heart. Black line - oxygen flux expressed per $\mathrm{mg}$ tissue wet weight. $M$ - malate, $G$ - glutamate, D - ADP, c - cytochrome c, $S$ - succinate, Rot - rotenone, AmA - antimycin A, TMPD $\mathrm{N}, \mathrm{N}, \mathrm{N}^{\prime}, \mathrm{N}^{\prime}$-tetramethyl-p-phenylenediamine dihydrochloride and ascorbate.

\section{Citrate synthase activity}

As citrate synthase activity may serve as a marker of mitochondrial content in the analyzed tissues and cells, we determined its activity in the samples aspirated from each oxygraph chamber (Kuznetsov et al. 2002, Larsen et al. 2012). The assay medium $(800 \mu \mathrm{l} ; 0.1 \mathrm{mmol} / \mathrm{l}$ 5,5-dithio-bis-(2-nitrobenzoic) acid, $0.25 \%$ Triton-X, $0.5 \mathrm{mmol} / 1$ oxalacetate, $0.31 \mathrm{mmol} / 1$ acetyl coenzyme A,
$5 \mu \mathrm{mo} / 1$ EDTA, $5 \mathrm{mmol} / 1$ triethanolamine hydrochloride, and $0.1 \mathrm{~mol} / 1$ Tris-HCl, $\mathrm{pH} 8.1$ ) was mixed with $200 \mu \mathrm{l}$ of the homogenized chamber content. The enzyme activity was measured spectrophotometrically at $412 \mathrm{~nm}$ and $30^{\circ} \mathrm{C}$ over $200 \mathrm{~s}$ and expressed in IU per mg tissue weight (Kuznetsov et al. 2002).

\section{Electrophysiology and contractility measurements}

Papillary muscles or trabeculae were dissected from the right or the left ventricle and placed into an experimental chamber perfused with oxygenated Tyrode solution $\left(36{ }^{\circ} \mathrm{C}\right)$ at a constant flow rate (6-10 ml/min). Tyrode solution contained (in $\mathrm{mmol} / \mathrm{l}$ ): $\mathrm{NaCl} 137 ; \mathrm{KCl} 4.5 ; \mathrm{MgCl}_{2} 1 ; \mathrm{CaCl}_{2} 2$; glucose 10; HEPES 5; and $\mathrm{pH}$ was adjusted to 7.4 with $\mathrm{NaOH}$. After stabilization period ( $30 \mathrm{~min}$ ), the steady-state contraction force and membrane potential were measured using an isometric force transducer (model F30; Hugo Sachs Electronik - Harvard Apparatus, GmBH, MarchHugstetten, Germany) and glass microelectrodes filled with $3 \mathrm{M} \mathrm{KCl}$ (resistance $>20 \mathrm{M} \Omega$; Microelectrode Puller P-1000, Sutter Instrument, CA, USA). Measurements were performed at stimulation frequencies 1, 2, 3, and $5 \mathrm{~Hz}$ (Pulsemaster Multi-Channel Stimulator A300; World Precision Instruments, Inc., Sarasota, FL, USA). After the signals in control solution had been obtained, propofol was added sequentially to the Tyrode solution to reach following concentrations: $0.02,0.05,0.1,0.2,0.3$, 0.4 , and $0.5 \mathrm{mmol} / \mathrm{l}$. Signals were recorded using the National Instruments data-acquisition hardware and software (National Instruments Corporation, Austin, TX, USA).

MATLAB 2014b (MathWorks Inc., Natick, MA, USA, 2014) was applied for offline signal analysis. The action potential duration (APD) was measured at the $50 \%$ and $90 \%$ levels of repolarization (APD50, APD90). Time course of the contraction force was described by three parameters: time-to-peak (TTP), time-to-50\%-relaxation (R50), and time-to-90\%relaxation (R90). The resting tension was taken as zero and then maximal amplitude of the contraction force (CFmax) was determined. All parameters were measured in at least ten beats, averaged, and the mean values were used for further analyses and comparisons.

\section{Data analysis and statistics}

Results are presented as mean $\pm \mathrm{SD}$ or SEM. Statistical differences were analyzed using software package STATISTICA Cz, version 8 (StatSoft Inc., 2007, 
Prague, Czech Republic) or OriginPro 8.5 (OriginLab Corporation, Northampton, MA, USA, 2011). After testing for the normality of distribution and homogeneity of variances, comparisons were made using one-way ANOVA (with post-hoc LSD or Bonferroni test) or Student's t-test, where appropriate. The results were considered significantly different when $p<0.05$. Fifty per cent effective concentration was calculated using OriginPro 8.5 from the dose-response curve fitting (with $95 \%$ confidence limits).

\section{Results}

\section{High resolution respirometry}

As shown in Figure 2, respiratory parameters PI, PI+II, PII, and CIV were significantly higher in the left ventricles than in the right ones. In the left ventricle, propofol significantly decreased oxygen consumption by Complex I (PI) at concentration $0.025 \mathrm{mmol} / 1$ and its effect was even more expressed at higher concentrations of the drug. In the right ventricle, propofol concentration significantly compromising mitochondrial ADP-stimulated respiration by Complex I (PI) was $0.05 \mathrm{mmol} / \mathrm{l}$. The effect of propofol on PI was concentration dependent; the EC50s calculated from the fitted dose-response curve were $0.023 \pm 0.05$ and $0.049 \pm 0.04 \mathrm{mmol} / 1$ for the left and right ventricle, respectively. In contrast, propofol did not have any substantial effect on Complex II or Complex IV related active respiration at concentrations lower than $0.5 \mathrm{mmol} / 1$ (Fig. 3A-D). Although the drug did not significantly impact the absolute values of the LEAK state, the OXPHOS control ratio $\mathrm{L} / \mathrm{P}$ increased with increasing propofol concentration suggesting lower efficiency of the phosphorylating process. In the left ventricle, control $\mathrm{L} / \mathrm{P}$ ratio was $0.19 \pm 0.01$ and it significantly increased from propofol concentration $0.05 \mathrm{mmol} / \mathrm{l} \quad(\mathrm{L} / \mathrm{P}=0.25 \pm 0.07) \quad$ to $\quad 0.5 \mathrm{mmol} / 1$ $(\mathrm{L} / \mathrm{P}=0.69 \pm 0.14)$. In the right ventricle, the OXPHOS control ratio in the intact samples was $0.21 \pm 0.02$ and reached significantly higher value at $0.025 \mathrm{mmol} / \mathrm{l}$ propofol concentration $(\mathrm{L} / \mathrm{P}=0.28 \pm 0.04)$ and further increased with rising drug level.

Citrate synthase activity was not affected by propofol at any concentration studied.

\section{Electrophysiology and contractility measurements}

In both heart ventricles there was no significant effect of propofol on the action potential duration (APD) at any of propofol concentrations, regardless of the stimulation frequency (1, 2, 3, or $5 \mathrm{~Hz}$, Fig. 4A). Kinetics of the contraction-relaxation cycle were not influenced by propofol except the highest concentration tested $(0.5 \mathrm{mmol} / \mathrm{l})$, at which the times to $50 \%$ relaxation (R50) and $90 \%$ relaxation (R90) were significantly prolonged in both left and right ventricles (Fig. 4B for stimulation frequency $1 \mathrm{~Hz}$ ). The time to peak of contraction force (TTP) remained unchanged at all propofol concentrations.

The application of propofol reduced contraction force at all stimulation frequencies used $(1,2,3$, and $5 \mathrm{~Hz}$, Fig. 5A-D). In the right ventricle, a significant decrease was observed at lower concentrations than in the left ventricle. However, the analysis of dose-response curves did not reveal any major difference in EC50 at any stimulation frequency: $0.33 \pm 0.02(1 \mathrm{~Hz}), \quad 0.24 \pm 0.03$ $(2 \mathrm{~Hz}), 0.21 \pm 0.04(3 \mathrm{~Hz}), 0.31 \pm 0.05(5 \mathrm{~Hz}) \mathrm{mmol} / 1$ in the left ventricle and $0.39 \pm 0.03(1 \mathrm{~Hz}), 0.23 \pm 0.03(2 \mathrm{~Hz})$, $0.22 \pm 0.03(3 \mathrm{~Hz})$, and $0.20 \pm 0.03(5 \mathrm{~Hz}) \mathrm{mmol} / 1$ in the right ventricle.

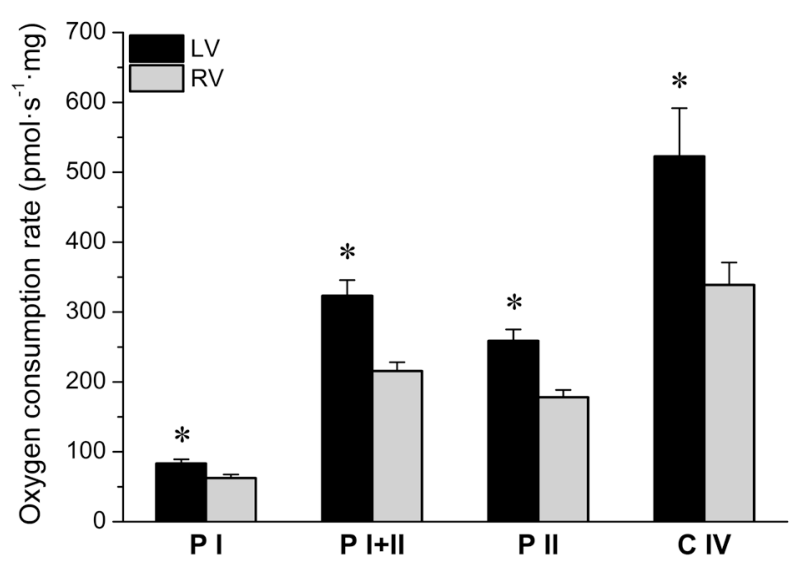

Fig. 2. Oxygen consumption rates in the state OXPHOS and Complex IV activity measured under control conditions in the right and left ventricles (RV, LV, respectively). PI - oxygen consumption rate in the state OXPHOS in the presence of ADP and substrates providing electrons to Complex I, i.e. glutamate and malate; PI+II - OXPHOS in the presence of ADP, glutamate, malate and a Complex II substrate, succinate; PII - OXPHOS in the presence of ADP and succinate, Complex I blocked by rotenone; CIV - Complex IV oxygen consumption rate in the presence of ascorbate and TMPD, corrected for autooxidation. Oxygen fluxes were expressed per $\mathrm{mg}$ tissue wet weight. $* \mathrm{P}<0.05$, LV compared to RV.

\section{Discussion}

The results of the present study indicate that propofol, in clinically relevant concentrations, substantially affects mitochondrial respiration and thus phosphorylation capacity in the mammalian heart. Compromised energy supply can contribute to the well-known effects of propofol on the cardiac contractility. 

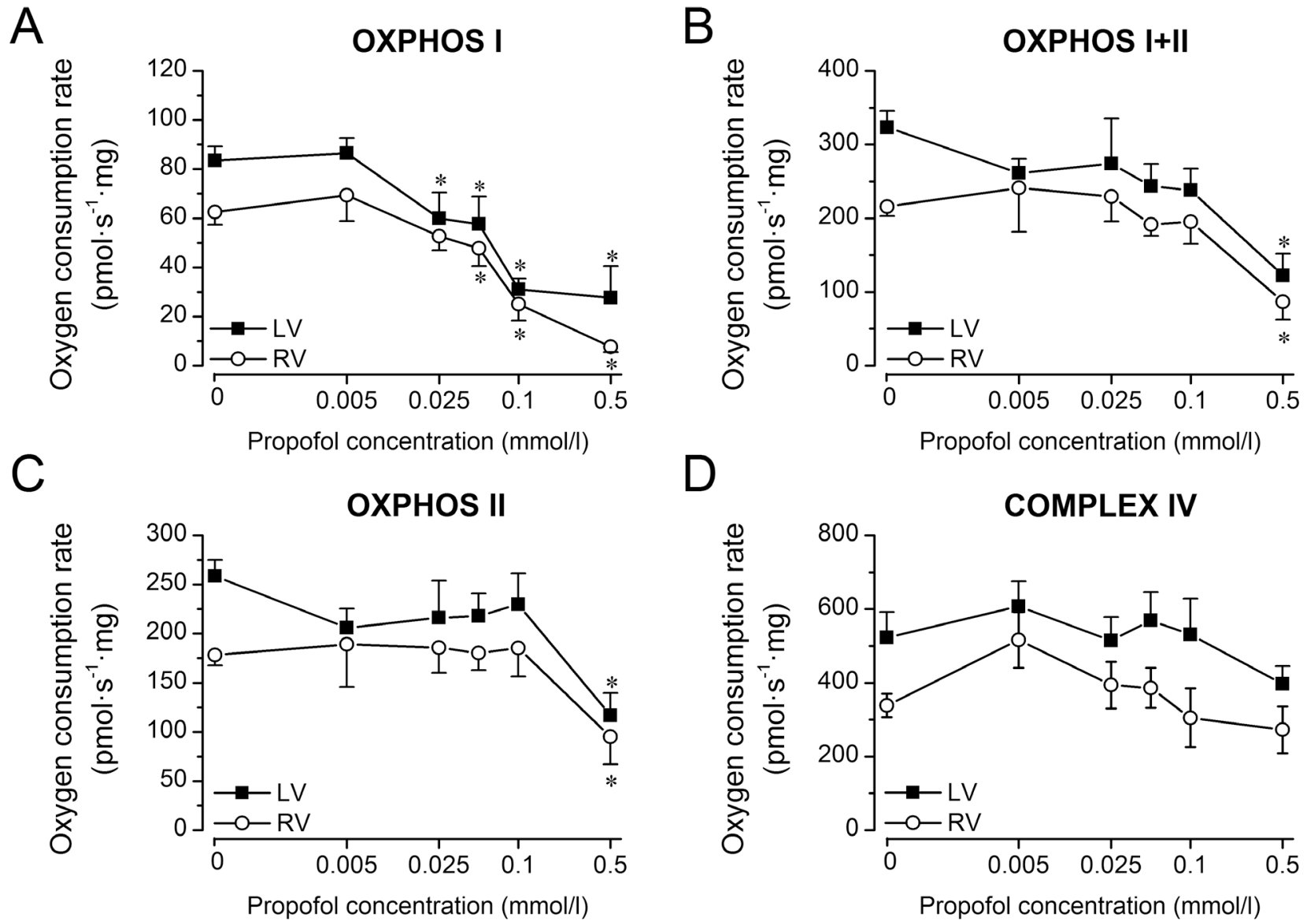

Fig. 3. Respiration of the permeabilized fibers isolated from the left (LV) and right ventricles (RV; cca $1 \mathrm{mg} / \mathrm{ml}$ ). Oxygen consumption was measured in MiR06 medium as described in Materials and Methods. Propofol effect was tested in concentrations 0.005, 0.025, 0.05, 0.1 , and $0.5 \mathrm{mmol} / \mathrm{l}$. A. Respiration after malate $(2 \mathrm{mmol} / \mathrm{l})$, glutamate $(10 \mathrm{mmol} / \mathrm{l})$, and ADP $(5 \mathrm{mmol} / \mathrm{l} ; \mathrm{PI})$. B. Oxygen consumption after malate, glutamate, ADP, and succinate $(10 \mathrm{mmol} / \mathrm{l} ; \mathrm{PI}+\mathrm{II})$. C. Active respiration after ADP, succinate rotenone $(0.5 \mu \mathrm{mol} / \mathrm{l} ; \mathrm{PII})$. D. Oxygen consumption after antimycin A $(2.5 \mu \mathrm{mol} / \mathrm{l})$, ascorbate $(2 \mathrm{mmol} / \mathrm{l})$, and TMPD $(0.5 \mathrm{mmol} / \mathrm{l}$; Complex IV). * P<0.05, significantly different from the respective control.

A

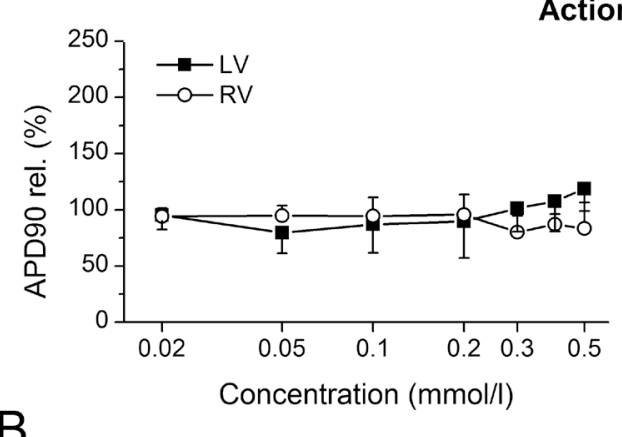

B

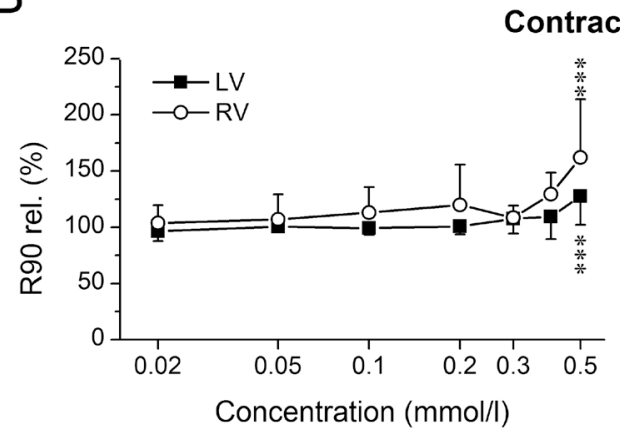

Fig. 4. Effect of propofol on the time course of action potential and contraction force. A. Action potential duration at $90 \%$ level of repolarization in the left (LV) and right (RV) ventricle at stimulation frequency of $1 \mathrm{~Hz}$ at various propofol concentrations expressed as a percentage of values obtained in control solution. Right panel - representative membrane potential traces in solution with $(0.5 \mathrm{mmol} / \mathrm{l})$ and without propofol. B. Time-to-90 \%-relaxation repolarization in left (LV) and right (RV) ventricle at stimulation frequency $1 \mathrm{~Hz}$ at various propofol concentrations expressed as a percentage of values obtained in control solution. Right panel - representative contraction traces in solution with $(0.5 \mathrm{mmol} / \mathrm{l})$ and without propofol. $* * * \mathrm{P}<0.001$, significantly different from the control. 
A

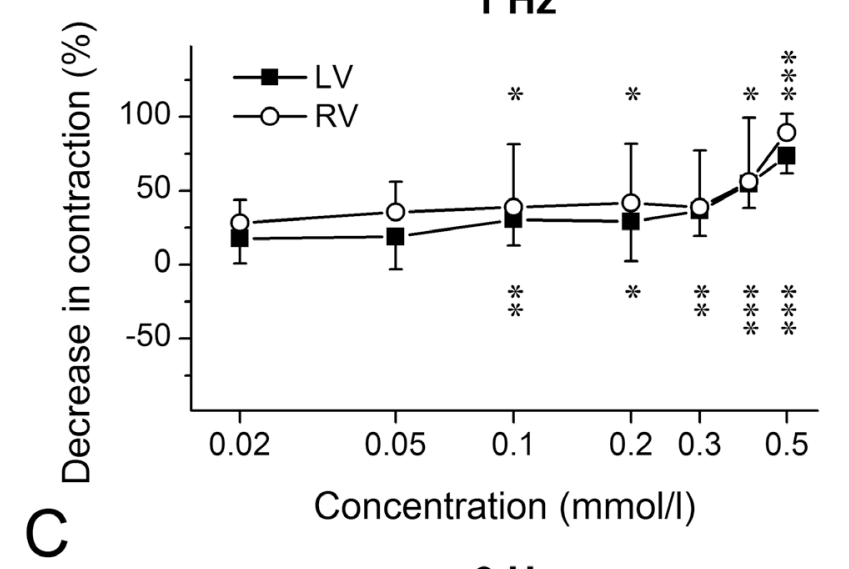

$3 \mathrm{~Hz}$

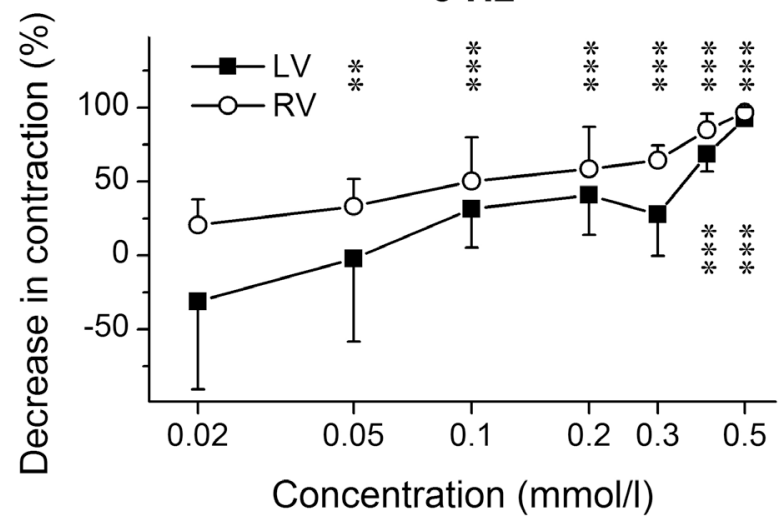

B

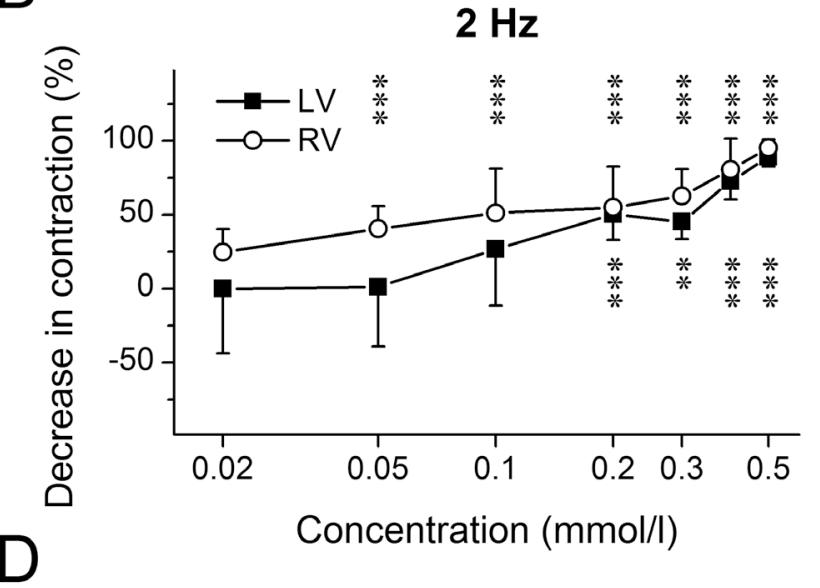

$5 \mathrm{~Hz}$

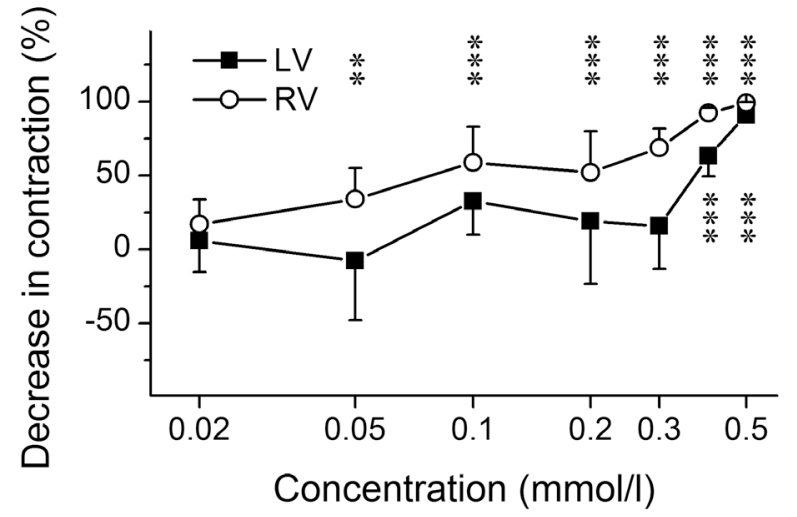

Fig. 5. Concentration dependence of the negative inotropic effect of propofol at different stimulation frequencies. Decrease in contraction in the left (LV; full squares) and right (RV; open circles) ventricle at stimulation frequencies 1 (A), 2 (B), 3 (C), and $5 \mathrm{~Hz}$ (D) expressed as a percentage of values obtained in control solution. $* \mathrm{P}<0.05, * * \mathrm{P}<0.01, * * * \mathrm{P}<0.001$, significantly different from the control.

Plasma concentrations of propofol determined in anesthetized patients range from 5 to $50 \mu \mathrm{mol} / 1$, those above $30 \mu \mathrm{mol} / 1$ are frequently considered high (Soehle et al. 2015). It should be noted that in human plasma, propofol is extensively bound to albumin and red blood cells and its free fraction represents only 1 to $5 \%$ of the total concentration, i.e. 0.05 to $2.5 \mu \mathrm{mol} / 1$ (Mazoit and Samii 1999, Dawidowicz et al. 2008). The range of concentrations used in our experiments was selected according to known propofol levels in humans and rats and with regard to concentrations reported to cause significant changes in cardiac functions (Grounds et al. 1985). The lowest concentration used in our oxygraphic experiments, i.e. $5 \mu \mathrm{mol} / 1$ was still higher than that of free propofol calculated from higher total drug level. Nevertheless, we still consider our concentrations clinically relevant for several reasons: 1) During induction of general anesthesia, propofol free concentration can exceed several fold the steady state values (Bienert et al. 2012). 2) Free fraction of propofol can be increased by various drugs that could bind to the same site on albumin, conformational alterations of molecular albumin or changes in plasma protein concentration that also limit propofol binding to albumin (Dawidowicz et al. 2008). 3) Solution MiR06 used in our experiments contained $1 \mathrm{~g} / 1$ of albumin (fatty acid free, globulin free) that could bind substantial portion of propofol added into the oxygraph chambers. One gram of albumin per liter represents approx. $15 \mu \mathrm{mol}$ of binding sites for propofol that is normally bound to the drug site I in close proximity to one of fatty acid binding sites with high affinity (Simard et al. 2006).

A limited number of experimental studies addressed the potential impact of propofol on mitochondrial respiration in the heart, although druginduced depression of cardiac function is known and feared side-effect of propofol. In the isolated rat heart mitochondria, propofol decreased both the 
transmembrane potential and ATP synthesis, however at concentrations by far exceeding those reported for free drug fraction during general anesthesia (Branca et al. 1995). Shao et al. (2008) reported no effect of propofol at concentration $100 \mu \mathrm{mol} / \mathrm{l}$ on the activities of the respiratory complexes in mitochondria isolated from the rat heart. In the same concentration, propofol protected mitochondrial function and decreased cardiac injury by prevention of cardiolipin peroxidation during ischemia and reperfusion (Shao et al. 2008). In our study, we used mitochondria in situ, i.e. in permeabilized muscle fibers, where the total population of mitochondria with preserved intracellular interactions is accessible for determination of oxygen consumption (Doerrier et al. 2016).

Our study has not revealed any change in action potential duration at any of the propofol concentrations used. The data concerning the effect of propofol on electrophysiological parameters of the rat heart are scarce. A single study documents no change in duration of action potential of the rat right ventricular papillary muscle up to concentration of propofol $300 \mu \mathrm{mol} / 1$ (Azuma et al. 1993). However, studies on isolated cardiomyocytes demonstrated significant inhibition of ICaL at propofol concentrations $100 \mu \mathrm{mol} / 1$ (Liu et al. 2008) and even $25 \mu \mathrm{mol} / \mathrm{l}$ (Zhou et al. 1997). Moreover, there are also data documenting some impact of propofol on potassium currents in the rat ventricular cardiomyocytes. Delayed rectifier $\mathrm{K}^{+}$current was decreased at $36 \mu \mathrm{mol} / 1$ of propofol in the clonal cardiac cells $\mathrm{H} 9 \mathrm{c} 2$ established from embryonic ventricle (Liu et al. 2008), but not at concentration approaching clinical values, when measured in rat isolated ventricular cardiomyocytes (2.5 $\mathrm{mol} / \mathrm{l}$; Carnes et al. 1997). Our results are not in conflict with these findings, since decreases in calcium and potassium membrane currents have opposite effects on action potential duration (Lee et al. 2016) and may therefore cancel each other.

The present study shows that contractility of the rat ventricular myocardium is significantly inhibited at propofol concentration $50 \mu \mathrm{mol} / \mathrm{l}$. The $50 \%$ effective concentrations at the most relevant stimulation frequency $3 \mathrm{~Hz}$ were 210 and $230 \mu \mathrm{mol} / \mathrm{l}$ in the left and right ventricles, respectively. Studies on the effect of propofol on the force of myocardial contraction are relatively numerous, but extremely controversial in relation to the mammalian species or experimental approach used (multicellular preparations, isolated cardiomyocytes). In the rat heart papillary muscle, no contractioncompromising effect of propofol was observed up to
$600 \mu \mathrm{mol} / 1$ (Azuma et al. 1993). However, their results were obtained under different experimental conditions, i.e. low temperature $\left(30^{\circ} \mathrm{C}\right)$ and stimulation frequency irrelevant for the rat heart $(0.5 \mathrm{~Hz})$. Majority of studies on isolated cardiomyocytes of different species including rat report EC50 for decrease in force of contraction of $\sim 50 \mu \mathrm{mol} / 1$ (Hamilton et al. 2000, Puttick and Terrar 1992). The decline in the force of contraction could not be fully explained by a decrease in L-type calcium current and was suggested to be contributed by other processes dealing with calcium turnover in the cell, like calcium sensitivity, modulation of $\mathrm{Na}-\mathrm{Ca}$ exchange activity, decrease in sarcoplasmic reticulum calcium load or impaired sensitivity of myofilaments to calcium ions (Hamilton et al. 2000, Wickley et al. 2007, Sprung et al. 2001, Wickley et al. 2006).

\section{Study limitations}

In the present study, the lowest concentration of propofol having significant effect on the heart function was $25 \mu \mathrm{mol} / 1$, which seems to be at least 10 times higher than is the free propofol concentration in the human plasma. However, proven accumulation of propofol in tissues, substantially higher plasma concentrations of the drug during induction of general anesthesia, duration of infusion, various comorbidities and unknown genetic background of mitochondrial dysfunction could lead to the heart dysfunction induced by even lower plasma concentrations of propofol (Bienert et al. 2012, Krajčová et al. 2015, Vanlander et al. 2015).

This study addressed neither putative genderrelated differences in the propofol sensitivity (Maeda et al. 2016), nor precise molecular mechanism of the drug effect at Complex I level or link between mitochondrial function and heart contraction.

\section{Conclusion}

Our study suggests that mechanism contributing to the impaired myocardial contraction during propofol anesthesia might include also mitochondrial dysfunction manifested by compromised activity of the respiratory Complex I. Our findings support hypothesis of potential critical involvement of mitochondrial dysfunction in the pathophysiology of the propofol infusion syndrome (Finsterer and Segall 2010).

\section{Conflict of Interest}

There is no conflict of interest. 


\section{Acknowledgements}

This study was supported by the National Sustainability Program I (NPU I) Nr. LO1503 provided by the Ministry of Education, Youth and Sports of the Czech Republic, the Charles University Research Fund (Nr. P36), the Specific Student Research Project Nr. 260281/2016 of the Charles University, Prague, and by the Grant Agency of the Czech Republic (project Nr. 15-15716S).

\section{References}

AZUMA M, MATSUMURA C, KEMMOTSU O: Inotropic and electrophysiologic effects of propofol and thiamylal in isolated papillary muscles of the guinea pig and the rat. Anesth Analg 77: 557-563, 1993.

BIENERT A, WICZLING P, GRZEŚKOWIAK E, CYWIŃSKI JB, KUSZA K: Potential pitfalls of propofol target controlled infusion delivery related to its pharmacokinetics and pharmacodynamics. Pharmacol Rep 64: 782-795, 2012.

BRANCA D, VINCENTI E, SCUTARI G: Influence of the anesthetic 2,6 -diisopropylphenol (propofol) on isolated rat heart mitochondria. Comp Biochem Physiol C Pharmacol Toxicol Endocrinol 110: 41-45, 1995.

BRYSON HM, FULTON BR, FAULDS D: Propofol. An update of its use in anesthesia and conscious sedation. Drugs 50: 513-559, 1995.

CARNES CA, MUIR WW 3RD, VAN WAGONER DR: Effect of intravenous anesthetics on inward rectifier potassium current in rat and human ventricular myocytes. Anesthesiology 87: 327-334, 1997.

DAWIDOWICZ AL, KOBIELSKI M, PIENIADZ J: Anomalous relationship between free drug fraction and its total concentration in drug-protein systems I. Investigation of propofol binding in model HSA solution. Eur $J$ Pharm Sci 34: 30-36, 2008.

DOERRIER C, GARCÍA JA, VOLT H, DÍAZ-CASADO ME, LUNA-SÁNCHEZ M, FERNÁNDEZ-GIL B, ESCAMES G, LÓPEZ LC, ACUÑA-CASTROVIEJO D: Permeabilized myocardial fibers as model to detect mitochondrial dysfunction during sepsis and melatonin effects without disruption of mitochondrial network. Mitochondrion 27: 56-63, 2016.

FINSTERER J, SEGALL L: Drugs interfering with mitochondrial disorders. Drug Chem Toxicol 33: 138-151, 2010.

GROUNDS RM, TWIGLEY AJ, CARLI F, WHITWAM JG, MORGAN M: The haemodynamic effects of intravenous induction. Comparison of the effects of thiopentone and propofol. Anaesthesia 40: 735-440, 1985.

HAMILTON DL, BOYETT MR, HARRISON SM, DAVIES LA, HOPKINS PM: The concentration-dependent effects of propofol on rat ventricular myocytes. Anesth Analg 91: 276-282, 2000.

KRAJČOVÁ A, WALDAUF P, ANDĚL M, DUŠKA F: Propofol infusion syndrome: a structured review of experimental studies and 153 published case reports. Crit Care 19: 398, 2015.

KUZNETSOV AV, STROBL D, RUTTMANN E, KÖNIGSRAINER A, MARGREITER R, GNAIGER E: Evaluation of mitochondrial respiratory function in small biopsies of liver. Anal Biochem 305: 186-194, 2002.

KUZNETSOV AV, SCHNEEBERGER S, SEILER R, BRANDACHER G, MARK W, STEURER W, SAKS V, USSON Y, MAIGREITER R, GNAIGER E: Mitochondrial defects and heterogeneous cytochrome c release after cardiac cold ischemia and reperfusion. Am J Physiol Heart Circ Physiol 286: 1633-1641, 2004.

LARSEN S, NIELSEN J, HANSEN CN, NIELSEN LB, WIBRAND F, STRIDE N, SCHRODER HD, BOUSHEL R, HELGE JW, DELA F, HEY-MOGENSEN M: Biomarkers of mitochondrial content in skeletal muscle of healthy young human subjects. $J$ Physiol 590: 3349-3360, 2012.

LEE YS, HWANG M, SONG JS, LI C, JOUNG B, SOBIE EA, PAK HN: The contribution of ionic currents to ratedependent action potential duration and pattern of reentry in a mathematical model of human atrial fibrillation. PLoS One 11: e0150779, 2016.

LIU YC, WANG YJ, WU SN: The mechanisms of propofol-induced block on ion currents in differentiated H9c2 cardiac cells. Eur J Pharmacol 590: 93-98, 2008.

MAEDA S, TOMOYASU Y, HIGUCHI H, HONDA Y, ISHII-MARUHAMA M, MIYAWAKI T: Female patients require a higher propofol infusion rate for sedation. Anesth Prog 63: 67-70, 2016.

MAZOIT JX, SAMII K: Binding of propofol to blood components: implications for pharmacokinetics and for pharmacodynamics. Br J Clin Pharmacol 47: 35-42, 1999. 
PESTA D, GNAIGER E: High-resolution respirometry: OXPHOS protocols for human cells and permeabilized fibers from small biopsies of human muscle. Methods Mol Biol 810: 25-58, 2012.

PUTTICK RM, TERRAR DA: Effects of propofol and enflurane on action potentials, membrane currents and contraction of guinea-pig isolated ventricular myocytes. Br J Pharmacol 107: 559-565, 1992.

RIOU B, BESSE S, LECARPENTIER Y, VIARS P: In vitro effects of propofol on rat myocardium. Anesthesiology 76: 609-616, 1992.

SHAO H, LI J, ZHOU Y, GE Z, FAN J, SHAO Z, ZENG Y: Dose-dependent protective effect of propofol against mitochondrial dysfunction in ischaemic/reperfused rat heart: role of cardiolipin. $\mathrm{Br} J$ Pharmacol 153: 1641-1649, 2008.

SIMARD JR, ZUNSZAIN PA, HAMILTON JA, CURRY S: Location of high and low affinity fatty acid binding sites on human serum albumin revealed by NMR drug-competition analysis. J Mol Biol 361: 336-351, 2006.

SOEHLE M, WOLF CF, PRISTON MJ, NEULOH G, BIEN CG, HOEFT A, ELLERKMANN RK: Comparison of propofol pharmacokinetic and pharmacodynamic models for awake craniotomy: a prospective observational study. Eur J Anaesthesiol 32: 527-534, 2015.

SPRUNG J, OGLETREE-HUGHES ML, MCCONNELL BK, ZAKHARY DR, SMOLSKY SM, MORAVEC CS: The effects of propofol on the contractility of failing and nonfailing human heart muscles. Anesth Analg 93: 550-559, 2001.

SZTARK F, ICHAS F, OUHABI R, DABADIE P, MAZAT JP: Effects of the anaesthetic propofol on the calciuminduced permeability transition of rat heart mitochondria: direct pore inhibition and shift of the gating potential. FEBS Lett 368: 101-104, 1995.

VAN KLARENBOSCH J, STIENEN GJ, DE RUIJTER W, SCHEFFER GJ, DE LANGE JJ: The differential effect of propofol on contractility of isolated myocardial trabeculae of rat and guinea-pig. Br J Pharmacol 132: 742-748, 2001.

VANLANDER AV, OKUN JG, DE JAEGER A, SMET J, DE LATTER E, DE PAEPE B, DACREMONT G, WUYTS B, VANHEEL B, De PAEPE P, JORENS PG, VAN REGENMORTEL N, VAN COSTER R: Possible pathogenic mechanism of propofol infusion syndrome involves coenzyme Q. Anesthesiology 122: 343-352, 2015.

WICKLEY PJ, SHIGA T, MURRAY PA, DAMRON DS: Propofol decreases myofilament $\mathrm{Ca}^{2+}$ sensitivity via a protein kinase C-, nitric oxide synthase-dependent pathway in diabetic cardiomyocytes. Anesthesiology 104: 978-987, 2006.

WICKLEY PJ, SHIGA T, MURRAY PA, DAMRON DS: Propofol modulates $\mathrm{Na}^{+}-\mathrm{Ca}^{2+}$ exchange activity via activation of protein kinase $\mathrm{C}$ in diabetic cardiomyocytes. Anesthesiology 106: 302-311, 2007.

YANG XY, ZHOU ZB, YANG L, ZHOU X, NIU LJ, FENG X: Hemodynamic responses during induction: comparison of Marsh and Schnider pharmacokinetic models. Int J Clin Pharmacol Ther 53: 32-40, 2015.

ZHOU W, FONTENOT HJ, LIU S, KENNEDY RH: Modulation of cardiac calcium channels by propofol. Anesthesiology 86: 670-675, 1997. 